\title{
Oropharyngeal tularemia
}

\section{Julia Steinrücken MD, Peter Graber MD}

Competing interests: None declared.

This article has been peer reviewed.

Affiliation: Department of Infectious Diseases, Basel University Medical Clinic, Liestal, Switzerland

Correspondence to: Julia Steinrücken, julia.steinruecken@gmail .com

CMAJ 2014. DOI:10.1503 /cmaj.122097
1 52-year-old woman from Switzerland presented with severe swelling of the lymph nodes on the left side of her neck. She reported having had a sore throat two months earlier, with fever and left-sided lymphadenitis. She had received amoxicillinclavulanic acid. Rapid tests for mononucleosis and group A streptococci had been performed, the results of which were negative.

Upon presentation, the patient was afebrile and in no distress. She had a large suppurative cervical lymph node and left-sided pharyngitis (Figure 1 and Appendix 1, available at www.cmaj.ca /lookup/suppl/doi:10.1503/cmaj.122097/-/DC1).

Laboratory investigations showed that the patient's lymphocyte count and C-reactive protein level were both normal. Biopsy samples taken from the lymph node showed necrotizing granulomatous lymphadenitis. We performed polymerase chain reaction (PCR) testing and bacterial culture, which ruled out cat-scratch disease and tuberculosis. However, PCR testing showed a positive result for Francisella tularensis, with molecular analysis identifying the organism as $F$. tularensis subsp. holarctica. We confirmed a diagnosis of

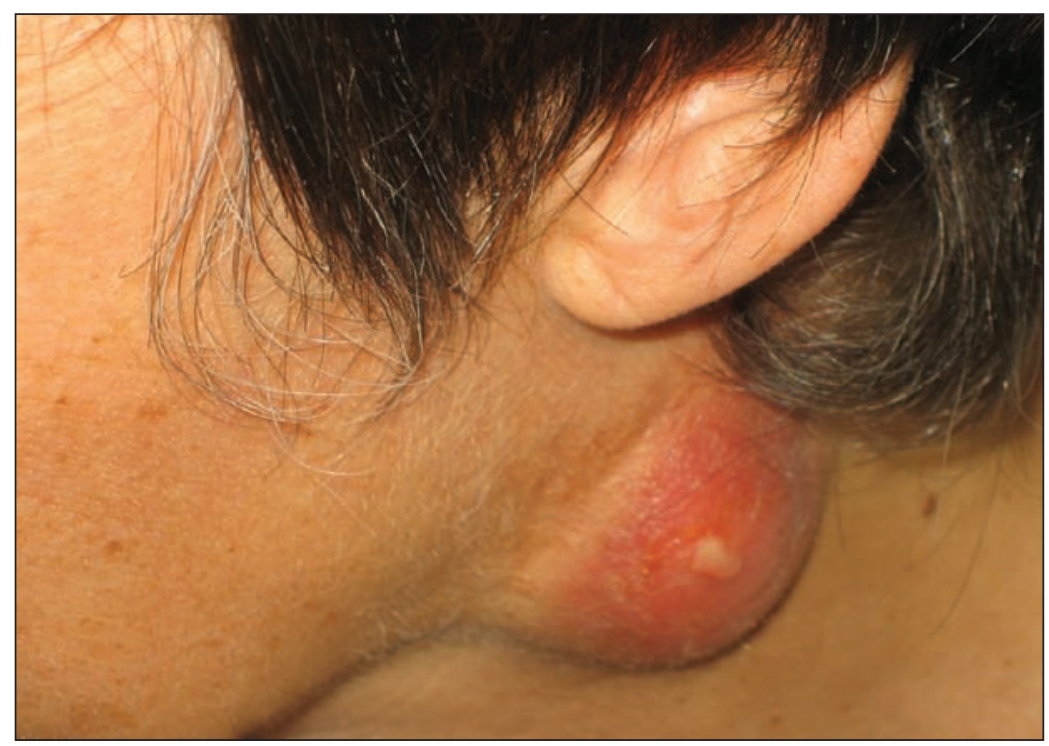

Figure 1: A large suppurative cervical lymph node with signs of apical perforation in a 52-year-old woman with oropharyngeal tularemia. tularemia by enzyme-linked immunosorbent assay, which showed high antibody titers (immunoglobulin M $834 \mathrm{U} / \mathrm{mL}$ and immunoglobulin $\mathrm{G}$ $431 \mathrm{U} / \mathrm{mL}$ [normal $0-15 \mathrm{U} / \mathrm{mL}$ ]). On further inquiry, we learned that our patient had cleaned the floor of an old barn that was heavily contaminated by dust and rodent feces. We prescribed a 6week course of doxycycline, and the patient fully recovered.

Tularemia is a re-emerging zoonosis throughout most of the northern hemisphere, with outbreaks described in the United States, Europe and Asia. ${ }^{1}$ The reported annual incidence rate is 0.03 0.06 per 100000 in North America and 0.2-0.5 per 100000 in Switzerland. Small rodents, such as rabbits, hares and voles, serve as animal reservoirs. Transmission of $F$. tularensis to humans can occur by arthropod bites, direct exposure through skin or mucous membrane while handling infected animals or contaminated materials, ingestion of contaminated water or food, or inhalation. The incubation period is usually $3-5$ days. ${ }^{1}$ Six different clinical syndromes have been described; our patient's presentation was compatible with the oropharyngeal form. ${ }^{2}$ The differential diagnosis includes toxoplasmosis; cat-scratch disease; mycobacterial, cytomegalovirus or Epstein Barr virus infection; streptococcal or staphylococcal disease; and lymphoma or metastatic cancer.

The dosing and duration of treatment with antimicrobial agents are not well defined. Aminoglycosides administered intravenously have traditionally been used. ${ }^{3}$ Tetracycline administered orally has been approved for use ${ }^{4}$ however, because it is bacteriostatic, a prolonged course of treatment is required. Quinolones are increasingly used and result in successful treatment. ${ }^{4}$

\section{References}

1. Sjöstedt A. Tularemia: history, epidemiology, pathogen physiology, and clinical manifestations. Ann N Y Acad Sci 2007;1105:1-29.

2. Ellis J, Oyston PC, Green M, et al. Tularemia. Clin Microbiol Rev 2002;15:631-46.

3. Enderlin G, Morales L, Jacobs RF, et al. Streptomycin and alternative agents for the treatment of tularemia: review of the literature. Clin Infect Dis 1994;19:42-7.

4. Weber IB, Turabelidze G, Patrick S, et al. Clinical recognition and management of tularemia in Missouri: a retrospective records review of 121 cases. Clin Infect Dis 2012;55:1283-90. 